\title{
PEMBUATAN VIDEO PROFIL PERUSAHAAN BERBASIS ANIMASI 3D DI PT. KRAKATAU INSAN MANDIRI
}

\author{
Riyan Hidayat ${ }^{1}$, Hendri Gunawan ${ }^{2}$, Diki Susandi ${ }^{3}$ \\ Universitas Serang Raya, Kota Serang - Banten \\ Email : rian.gembel.elit@gmail.com ${ }^{1}$, hendry@unsera.ac.id ${ }^{2}$, \\ unsera.diky@gmail.com ${ }^{3}$
}

\begin{abstract}
Multimedia as a medium of communication, information delivery, and promotion is one of the most popular technology fields. As a fields that are flexible and can be attractive, as well as pamper the human senses, multimedia can simultaneously affect humans visually, audio, and touch so that it can make consumers digest the message contained more optimally. One product that requires multimedia to improve its superiority is a company profile or profile company. In this case, PT. Krakatau Insan Mandiri seeks to introduce clearly as well as attractive to consumers through profile videos $3 D$ animation based company. The benefits are documentation and promotional media and information about the company profile of PT. Krakatau Insan Mandiri. In making this company profile video the author uses methodologies include: Literature Study, Analysis and Design of Systems, System Implementation, System Testing, and Documentation.
\end{abstract}

Keywords : Company Profile Videos, Multimedia, 3D Animation.

\section{PENDAHULUAN}

Profil Perusahaan merupakan penjelasan mengenai perusahaan secara umum. Di dalamnya berisi info visi dan misi sebuah perusahaan. Profil Perusahaan memiliki peranan cukup penting bagi sebuah perusahaan karena dapat mempresentasikan visi dan misi perusahaan atau apa yang ingin ditawarkan kepada konsumen. Selain itu manfaat lain dari profil perusahaan sebagai sarana presentasi adalah dapat mempersingkat pertemuan sehingga klien tidak perlu bertanya secara detail tentang profil, visi, dan misi perusahaan secara langsung.

Perkembangan dan kemajuan teknologi informasi semakin pesat pada pengembangan Animasi 3D yang sudah populer di masyarakat. Animasi 3D merupakan penciptaan gambar bergerak dalam ruang digital 3D. Penggunaan Animasi 3D untuk saat ini bukan hanya untuk game saja, tapi bisa di manfaatkan sebagai sarana media informasi yang telah melebar ke banyak aspek di dalam perusahaan sehingga mengalami sebuah perkembangan yang signifikan. Hal ini 
dikarenakan video animasi sangat menarik sehingga cepat di terima kepada para konsumen.

Banyaknya industri pabrik sekarang berlomba-lomba memperkenalkan perusahaannya kepada para konsumen. Salah satunya yaitu di PT. Krakatau Insan Mandiri yang terletak di daerah Kota Cilegon. Tetapi profil perusahaan di PT. Krakatau Insan Mandiri masih menggunakan buku sehingga sulit untuk memperkenalkan tentang profil, visi, dan misi kepada konsumen. Di PT. Krakatau Insan Mandiri juga belum memanfaatkan teknologi informasi dalam pengenalan profil perusahaannya. Selain itu penulis juga ingin memberi kontribusi di perusahaan PT. Krakatau Insan Mandiri untuk membantu memperkenalkan kepada para konsumen melalui penerapan berbasis animasi 3D.

Dalam hal ini PT. Krakatau Insan Mandiri berupaya memperkenalkan secara jelas sekaligus menarik kepada para konsumen melalui profil perusahaan berbasis animasi 3D. Sehingga dapat memperkenalkan profil, visi dan misi secara jelas dan cepat diterima kepada para konsumen. Maka profil perusahaan berbasis animasi 3D ini harus di buat semenarik mungkin.

\section{Identifikasi Masalah}

Sesuai dengan latar belakang masalah di atas maka peneliti menentukan identifikasi masalahnya sebagai berikut:

1. Profil Perusahaan di PT. Krakatau Insan Mandiri masih menggunakan buku sehingga sulit untuk memperkenalkan tentang data perusahaan, visi, dan misi kepada konsumen.

2. Belum memanfaatkan teknologi informasi dalam pengenalan profil perusahaan PT. Krakatau Insan Mandiri.

\section{Rumusan Masalah}

Sesuai dengan latar belakang masalah di atas maka peneliti merumuskan masalahnya sebagai berikut:

1. Bagaimana membuat profil perusahaan berbasis animasi 3D yang sederhana untuk memudahkan konsumen mengenal PT. Krakatau Insan Mandiri ? 
2. Bagaimana mengimplementasikan profil perusahaan berbasis animasi 3D pada PT. Krakatau Insan Mandiri ?

\section{Batasan Masalah}

Adapun batasan masalah dalam penelitian ini adalah sebagai berikut:

1. Pembuatan profil perusahaan berbentuk animasi 3D yang mencakup data, visi dan misi di perusahaan PT. Krakatau Insan Mandiri.

2. Lokasi penelitian untuk video profil perusahaan berbasis animasi 3D hanya dalam ruang lingkup PT. Krakatau Insan Mandiri.

3. Video akan dibuat menggunakan aplikasi Corel Draw, MakeHuman, Blender 3D, Adobe Premiere Pro dan Audacity.

\section{METODOLOGI PENELITIAN}

\section{Metode Perancangan Multimedia Versi Luther Sutopo}

Perancangan multimedia dilakukan berdasarkan 6 tahap, yaitu konsep, perancangan, pengumpulan bahan, pembuatan, pengujian dan distribusi. Untuk membentuk aplikasi multimedia, bermacam-macam peralatan dapat digunakan, baik software maupun hardware. Perangkat lunak yang secara khusus ditujukan untuk membuat aplikasi multimedia disebut multimedia authoring system (atau sering disebut authoring software). Beberapa contoh yang tergolong sebagai authoring software yaitu Authoware, Quest, Icon Author, dan Multimedia Director.

Banyak Metodelogi perancangan perangkat lunak (software engineering), tetapi tidak tepat di terapkan pada perancangan perangkat lunak berbasis multimedia. Setidaknya ada dua metodelogi biasa yang dapat digunakan untuk perancangan perangkat lunak berbasis multimedia. Salah satunya adalah menurut Sutopo (2003), yang berpendapat bahwa metodelogi perancangan multimedia terdiri dari 6 tahapan, yaitu concept, design, material collecting, assembly, testing dan distribution Seperti gambar berikut ini berikut ini: 


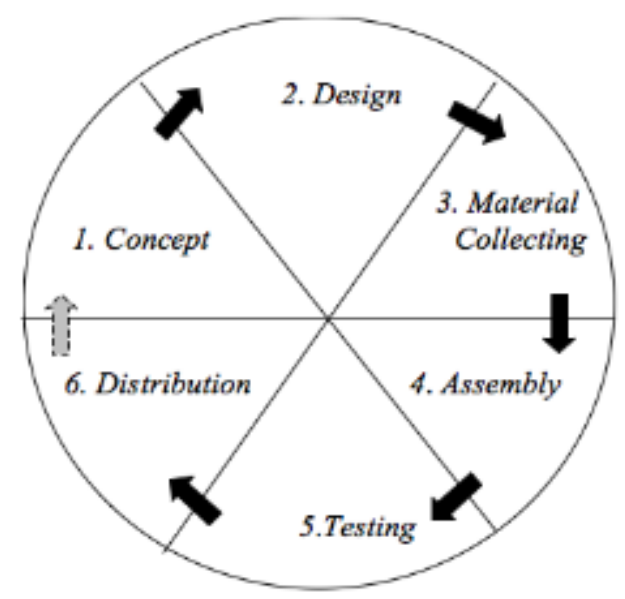

Gambar 1. Metode Perancangan Luther Sutopo

1) Concept, tahap concept (konsep) adalah tahap untuk menentukan tujuan dan siapa pengguna program (identifikasi audience). Selain itu menentukan macam aplikasi (presentasi, interaktif, dan lain-lain) dan tujuan aplikasi (hiburan, pelatihan, pembelajaran, dan lain-lain).

2) Design, design (perancangan) adalah tahap membuat spesifikasi mengenal arsitektur program, gaya, tampilan dan kebutuhan material / bahan untuk program.

3) Material Collecting, material collecting adalah tahap dimana pengumpulan bahan yang sesuai dengan kebutuhan dilakukan. Tahap ini dapat dikerjakan paralel dengan tahap assembly. Pada beberapa kasus, tahap Material Collecting dan tahap Assembly akan dikerjakan secara linear tidak paralel.

4) Assembly, assembly (pembuatan) adalah tahap dimana semua objek atau bahan multimedia dibuat. Pembuatan aplikasi didasarkan pada tahap design.

5) Testing, testing dilakukan setelah selesai tahap pembuatan (assembly) dengan menjalankan aplikasi / program dan dilihat apakah ada kesalahan atau tidak. Tahap ini disebut juga sebagai tahap pengujian alpha (alpha test) dimana pengujian dilakukan oleh pembuat atau lingkungan pembuatnya sendiri.

6) Distribution, distribusi adalah tahapan dimana aplikasi disimpan dalam suatu media penyimpanan. Pada tahap ini jika media penyimpanan tidak cukup untuk menampung aplikasinya, maka dilakukan kompresi terhadap aplikasi tersebut. (Munir, 2015). 


\section{Langkah-Langkah Penelitian}

1) Studi Literatur

Pada tahap ini penulisan dimulai dengan studi kepustakaan yaitu proses pengumpulan bahan referensi, mempelajari serta menggali informasi baik dari buku, artikel, jurnal, makalah, maupun situs internet tentang animasi 3D.

2) Analisis dan Perancangan Sistem

Pada tahap analisis dan perancangan sistem dilakukan analisis proses pembuatan profil perusahaan. Untuk mengetahui bagaimana pembuatan profil perusahaan yang berbasis animasi 3D. Alur kerja sistemnya dalam bentuk luther-sutopo.

3) Implementasi Sistem

Pada tahap ini sistem diimplementasikan dengan menggunakan Corel Draw, MakeHuman, Blender 3D, Adobe Premiere Pro dan Audacity.

4) Pengujian Sistem

Melakukan pengujian terhadap video yang telah dibuat serta menguji kebenarannya dari pembuatan profil perusahaan berbasis animasi 3D dengan Alpha dan Beta Testing.

5) Dokumentasi

Peneliti mendokumentasikan hasil analisis dan implementasi secara tertulis.

\section{Kerangka Pemikiran}

Kerangka pikir dalam penelitian ini bertujuan sebagai alur yang berperan dalam pembuatan aplikasi, mulai dari identifikasi masalah, metode dan software yang digunakan, pengujian, implementasi, dan hasil. Berikut adalah penjelasannya:

\section{1) Identifikasi Masalah}

Sesuai dengan latar belakang masalah diatas maka penulis menentukan identifikasi masalahnya sebagai berikut:

a. Profil Perusahaan di PT. Krakatau Insan Mandiri masih menggunakan manual (menggunakan buku) sehingga sulit untuk memperkenalkan tentang profil, visi, dan misi kepada konsumen. 
b. Belum adanya Profil Perusahaan berbasis Animasi 3D di PT. Krakatau Insan Mandiri.

2) Metode

Metode yang digunakan adalah perancangan perangkat lunak versi LutherSutopo, karena metode ini adalah metode yang sesuai pada pembuatan profil perusahaan dalam penelitian.

3) Software

Ada 5 software yang akan digunakan dalam penelitian ini, yaitu Corel Draw, MakeHuman, Blender 3D, Adobe Premiere Pro dan Audacity.

4) Pengujian

Melakukan pengujian terhadap video yang telah dibuat serta menguji kebenarannya dari pembuatan profil perusahaan berbasis Animasi 3D dengan Alpha dan Beta Testing.

5) Implementasi

Video yang dibuat akan di implementasikan dengan format mp4 karena format ini cukup universal dan standar.

6) Hasil

Video yang dibuat akan di upload di youtube guna memperkenalkan perusahaan kepada para konsumen sehingga dapat memberikan informasi dan dapat diterima kepada para konsumen.

\section{PEMBAHASAN}

\section{Konsep (Concept)}

Pada perancangan konsep video profil perusahaan ini diantaranya adalah mengidentifikasi audiens dan tujuan.

1) Identifikasi Audiens

Dalam video ini ditargetkan untuk para calon konsumen yang ingin menggunakan barang dan jasa dari PT. Krakatau Insan Mandiri. Target Audiens dalam video ini yaitu perusahaan-perusahaan yang membutuhkan barang dan jasa di PT. Krakatau Insan Mandiri. Perusahaan ini juga pernah bekerja sama dengan perusahaan-perusahaan besar di Cilegon yaitu PT. 
Artas, PT. Krakatau Bandar Samudera dan PT. Krakatau Industrial Estate Cilegon.

2) Tujuan

Video profil perusahaan ini ingin memperkenalkan perusahaan yang bergerak dibidang Suplier tentang Profil, Visi, Misi dan Motto kepada para konsumen sehingga dapat memberikan informasi secara jelas dan dapat diterima kepada para konsumen.

\section{Perancangan (Design)}

Tahap ini biasanya menggunakan storyboard untuk menggambarkan deskripsi scene dengan mencantumkan semua objek multimedia dan tautan ke scene lain.

\section{1) Konsep Perancangan}

Konsep sangat dibutuhkan dalam perancangan video profil perusahaan, adapun konsep dalam perancangan video profil perusahaan berbasis animasi 3d sebagai berikut:

a) Scene 1, dalam scene pertama akan menampilkan intro awal berbentuk teks "Profil Perusahaan dalam Animasi 3D" dengan durasi 8 detik.

b) Scene 2, scene kedua yaitu menampilkan intro berbentuk teks logo dan nama perusahaan PT. Krakatau Insan Mandiri dengan durasi 7 detik.

c) Scene 3, scene ketiga menampilkan karakter sambil berjalan menuju kantor dengan background kantor PT. Krakatau Insan Mandiri dan memberikan informasi tentang perusahaan PT. Krakatau Insan Mandiri dengan durasi 10 detik.

d) Scene 4, scence keempat menampilkan letak berdirinya PT. Krakatau Insan Mandiri dan menginformasikan tentang pertama kali berdirinya PT. Krakatau Insan Mandiri dengan durasi 9 detik.

e) Scene 5, dalam scene kelima yaitu menginformasikan tentang contoh barang dan jasa dari PT. Krakatau Insan Mandiri dengan durasi 19 detik.

f) Scene 6, dalam scene keenam yaitu menginformasikan tentang perusahaan apa saja yang pernah bekerja sama dengan PT. Krakatau Insan Mandiri dengan durasi 21 detik. 
g) Scene 7, dalam scene ketujuh yaitu menampilkan karakter dengan background kantor PT. Krakatau Insan Mandiri yang menginformasikan tentang visi, misi dan motto perusahaan PT. Krakatau Insan mandiri lalu penutup dengan durasi 41 detik.

h) Scene 8, dalam scene kedelapan yaitu menampilkan keterangan video profil perusahaan PT. Krakatau Insan Mandiri atau yang biasa kita sebut Credit Title dengan durasi 23 detik.

i) Scene 9, scene terakhir yaitu menampilkan profil riwayat hidup dari si pembuat video perusahaan animasi 3D dengan durasi 5 detik.

2) Storyboard

Tabel 1. Storyboard

\begin{tabular}{|c|c|c|c|l|}
\hline Scene & Sequence & Board & Durasi & Naskah \\
\hline 1 & 1 & Animasi teks 3D disertai \\
musik intro.
\end{tabular}




\begin{tabular}{|c|c|c|c|c|}
\hline Scene & Sequence & Board & Durasi & Naskah \\
\hline & 2 & 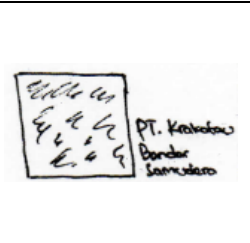 & 00:05 & $\begin{array}{l}\text { Animasi teks 3D dan foto } \\
\text { perusahaan (PT. Krakatau } \\
\text { Bandar Samudera) yang } \\
\text { pernah bekerjasama } \\
\text { diiringi musik. }\end{array}$ \\
\hline & 3 & 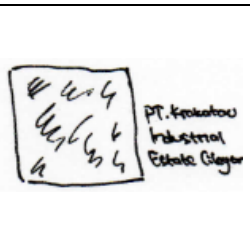 & $00: 05$ & $\begin{array}{l}\text { Animasi teks 3D dan foto } \\
\text { perusahaan (PT. Krakatau } \\
\text { Industrial Estate Cilegon) } \\
\text { yang pernah bekerjasama } \\
\text { diiringi musik. }\end{array}$ \\
\hline \multirow[t]{2}{*}{6} & 1 & & 00:03 & $\begin{array}{l}\text { Animasi karakter } 3 \mathrm{D} \\
\text { nampak kaki yang berjalan } \\
\text { menuju ruangan diiringi } \\
\text { musik. }\end{array}$ \\
\hline & 2 & & 00:03 & 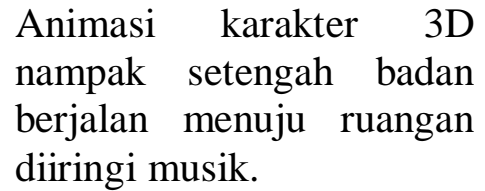 \\
\hline \multirow[t]{6}{*}{7} & 1 & & 00:06 & $\begin{array}{l}\text { Animasi karakter 3D yang } \\
\text { menginformasikan profil } \\
\text { perusahaan diiringi musik. }\end{array}$ \\
\hline & 2 & & $00: 04$ & $\begin{array}{l}\text { Animasi karakter 3D yang } \\
\text { menginformasikan contoh } \\
\text { barang dan jasa diiringi } \\
\text { musik. }\end{array}$ \\
\hline & 3 & & 00:06 & $\begin{array}{l}\text { Animasi karakter } 3 \mathrm{D} \text { yang } \\
\text { meninformasikan } \\
\text { perusahaan yang pernah } \\
\text { bekerjasama } \\
\text { musik. }\end{array}$ \\
\hline & 4 & & $00: 16$ & $\begin{array}{l}\text { Animasi karakter 3D yang } \\
\text { menginformasikan visi dan } \\
\text { misi perusahaan diiringi } \\
\text { musik. }\end{array}$ \\
\hline & 5 & - & $00: 16$ & $\begin{array}{l}\text { Animasi karakter 3D yang } \\
\text { menginformasikan motto } \\
\text { perusahaan diiringi musik. }\end{array}$ \\
\hline & 6 & & $00: 07$ & $\begin{array}{l}\text { Animasi karakter 3D yang } \\
\text { mengucapkan terima kasih } \\
\text { sebagai penutup diiringi } \\
\text { musik. }\end{array}$ \\
\hline
\end{tabular}




\begin{tabular}{|c|c|c|c|l|}
\hline Scene & Sequence & Board & Durasi & Naskah \\
\hline 8 & 1 & Animasi teks yang \\
& & & $\begin{array}{l}\text { Ans } \\
\text { bergerak dari bawah ke } \\
\text { atas untuk menampilkan } \\
\text { keterangan dari video } \\
\text { profil perusahaan diiringi } \\
\text { musik. }\end{array}$ \\
\hline 9 & 1 & $\begin{array}{l}\text { Animasi teks yang } \\
\text { menampilkan profil } \\
\text { pembuat video diiringi } \\
\text { musik penutup. }\end{array}$ \\
\hline
\end{tabular}

\section{Pengumpulan Material (Material Collecting)}

1) Analisa Kebutuhan Data

PT. Krakatau Insan Mandiri adalah perusahaan yang bergerak di bidang perdagangan dan jasa yang beralamatkan di Link. Kubang Laban Rt. 03 Rw. 02 No. 14 Kel. Panggung Rawi Cilegon, Banten. PT. Krakatau Insan Mandiri berdiri pada tahun 2013, tepatnya pada bulan april. Perusahaan ini pernah bekerja sama dengan perusahaan-perusahaan besar di cilegon seperti PT. Artas, PT. Krakatau Bandar Samudera dan PT. Krakatau Industrial Estate Cilegon. Contoh barang dan jasa dari PT. Krakatau Insan Mandiri yaitu berupa pipa gres, pipa oli, valve, welder, piping dan masih banyak lagi yang lainnya. Visi dari PT. Krakatau Insan Mandiri adalah menjadi perusahaan supplier dan jasa yang handal sedangkan misinya adalah memberikan jasa secara terintegrasi, dengan biaya yang kompetitif, tepat waktu dan aman untuk kepuasan pelanggan. PT. Krakatau Insan Mandiri mempunyai motto "kami siap untuk anda" jadi perusahaan ini akan selalu siap untuk permintaan para konsumen dan membuat kesan yang baik agar di percaya oleh perusahaan tersebut sehingga mereka puas dengan pelayanannya.

2) Analisa Kebutuhan Hardware

Tabel 2. Kebutuhan Hardware

\begin{tabular}{|l|l|}
\hline \multicolumn{1}{|c|}{ Perangkat Hardware } & \multicolumn{1}{c|}{ Spesifikasi } \\
\hline Laptop & Lenovo G40 \\
\hline Sistem Operasi & Windows 10 Enterprise 64-Bit \\
\hline Prosesor & AMD A8-6410 APU with \\
& AMD Radeon R5 Graphics \\
\hline Memori & RAM DDR3 4GB \\
\hline
\end{tabular}


3) Analisa Kebutuhan Software

Tabel 3. Kebutuhan Software

\begin{tabular}{|l|l|}
\hline \multicolumn{1}{|c|}{ Perangkat Software } & \multicolumn{1}{c|}{ Harga } \\
\hline Blender 3D & Open Source \\
\hline MakeHuman & Open Source \\
\hline Corel Draw & Open Source \\
\hline Audacity & Open Source \\
\hline Adobe Premiere Pro & $\begin{array}{l}\text { Rp 2.670.000 (www.adobe.com) } \\
\text { diakses tanggal 29-05-2018 }\end{array}$ \\
\hline
\end{tabular}

\section{Pembuatan (Assembly)}

Dalam tahap ini proses pembuatan animasi mulai dilakukan, adapun proses pembuatan animasi ini terdiri dari beberapa tahapan mulai dari desain, modelling 3D, animation, dubbing, rendering, finishing dan deskripsi hasil.

1) Desain

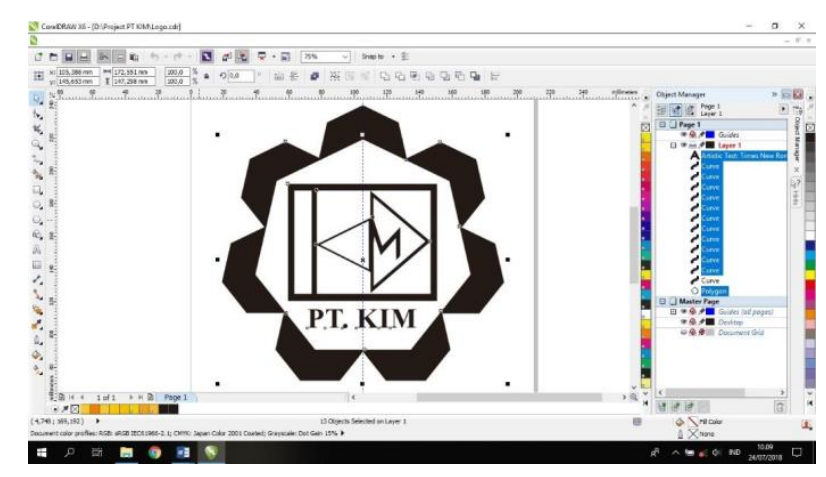

Gambar 2. Desain Logo Perusahaan

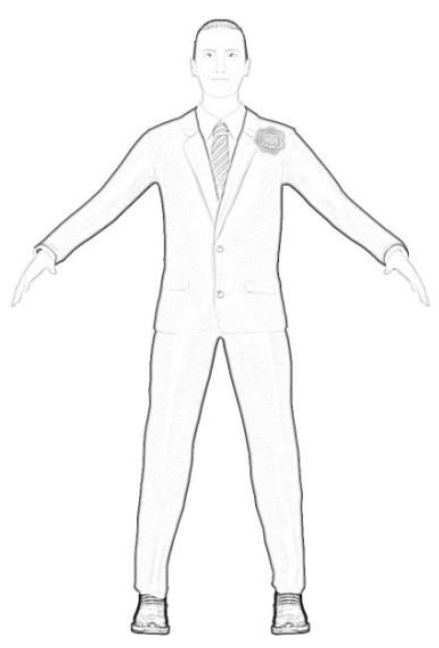

Gambar 3. Desain Karakter 
2) Modelling $3 D$

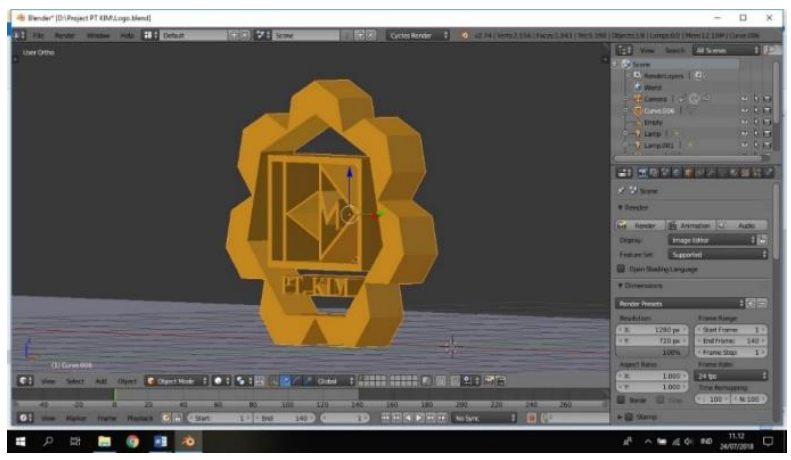

Gambar 4. Proses Modelling Logo Dengan Menggunakan Blender

3) Animation

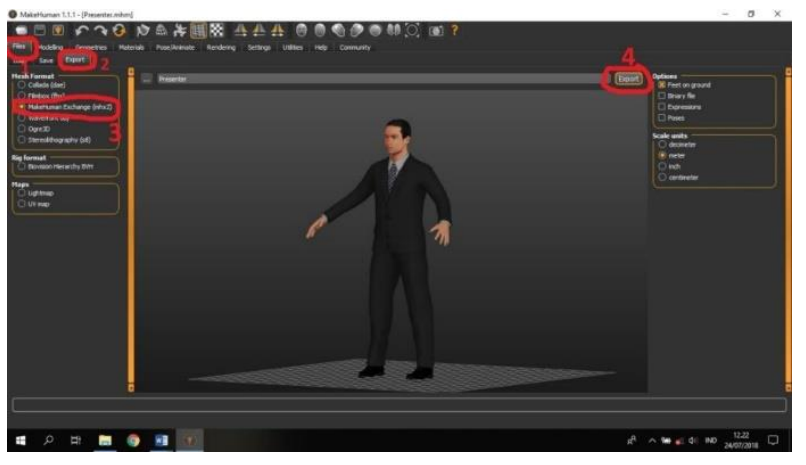

Gambar 5. Proses Animation Karakter

4) Dubbing

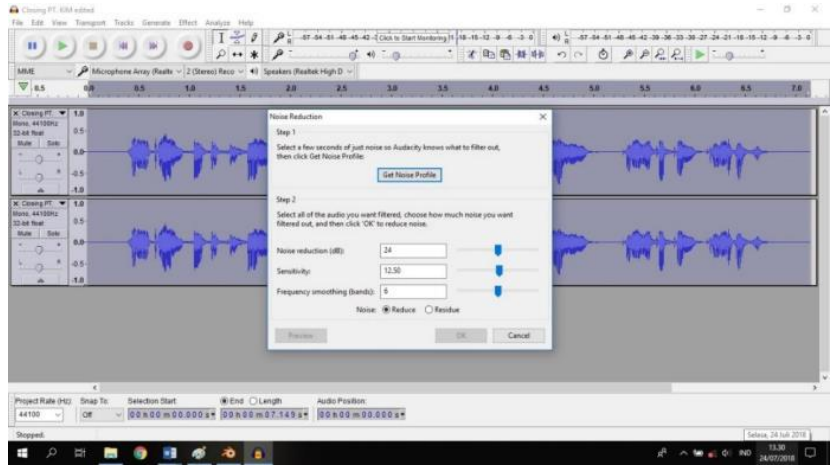

Gambar 6. Proses Dubbing Suara 
5) Rendering

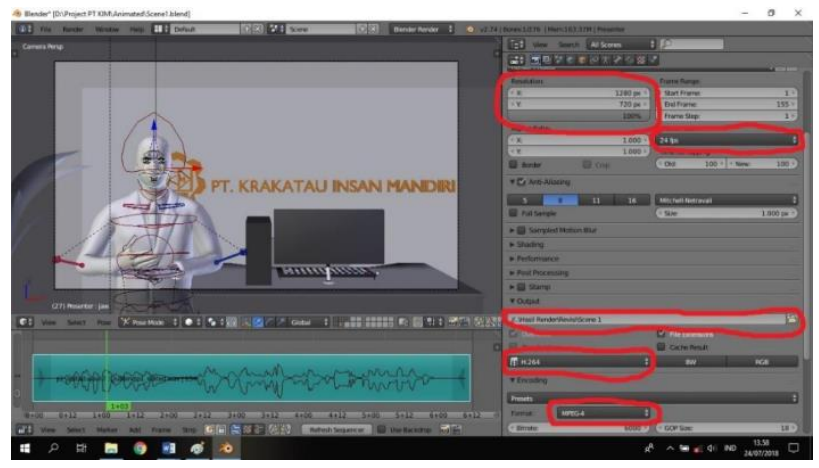

Gambar 7. Proses Rendering Karakter

6) Finishing

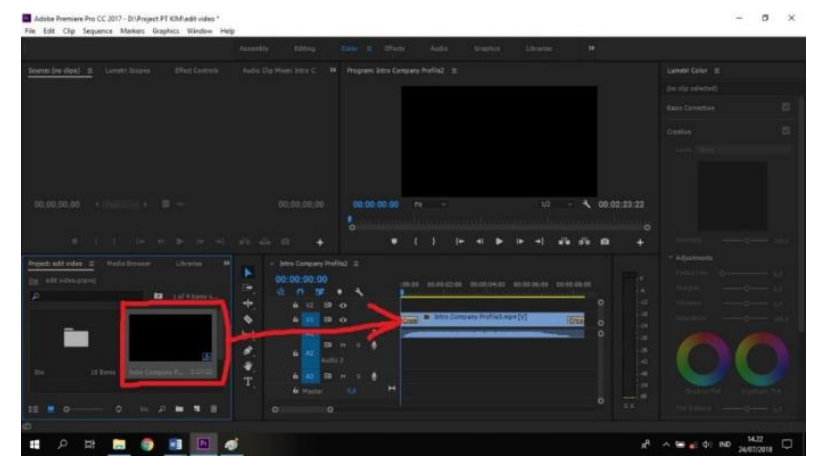

Gambar 8. Proses Finishing

7) Deskripsi Hasil

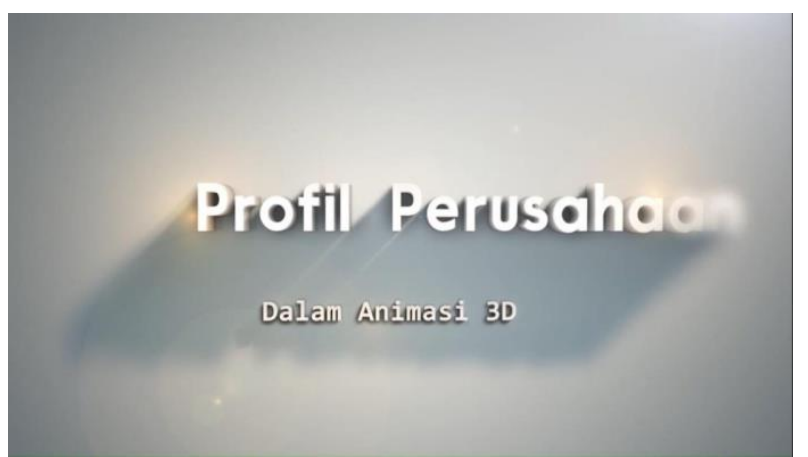

Gambar 9. Tampilan Hasil Video Saat Intro Awal 


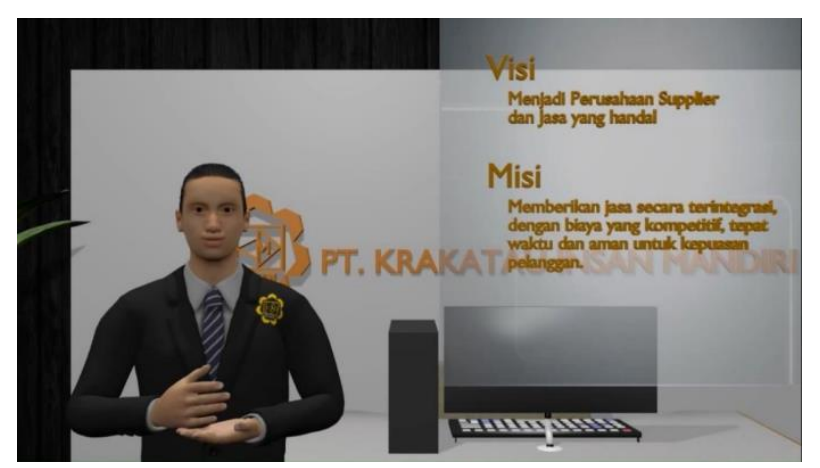

Gambar 10. Tampilan Hasil Video Saat Menginformasikan Visi dan Misi

\section{Pengujian (Testing)}

Pada tahap ini, pengembangan aplikasi multimedia memasuki tahapan pengujian. Hasil pengujian sebagai berikut:

Tabel 4. Hasil Pengujian Dengan Beberapa Software

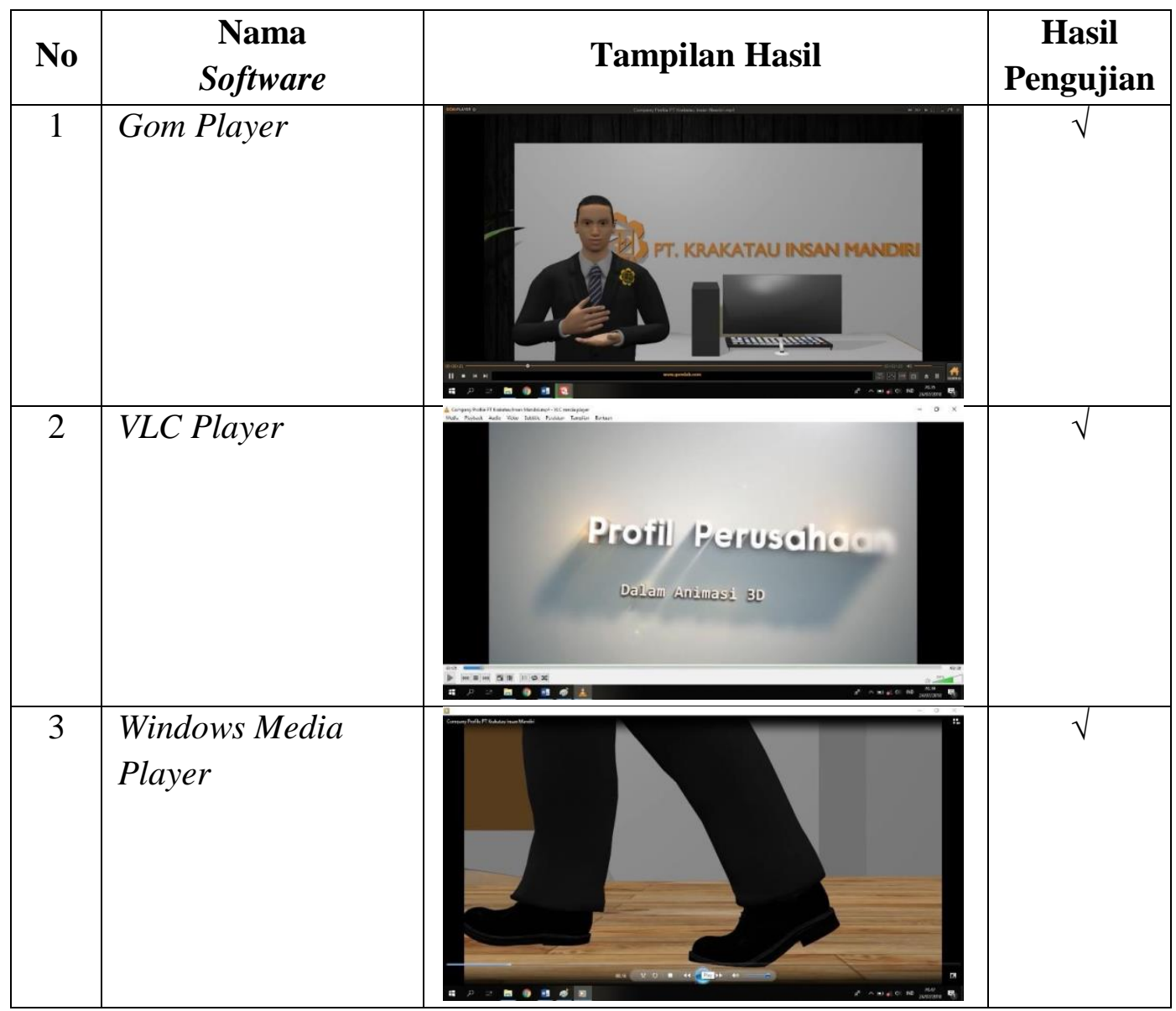




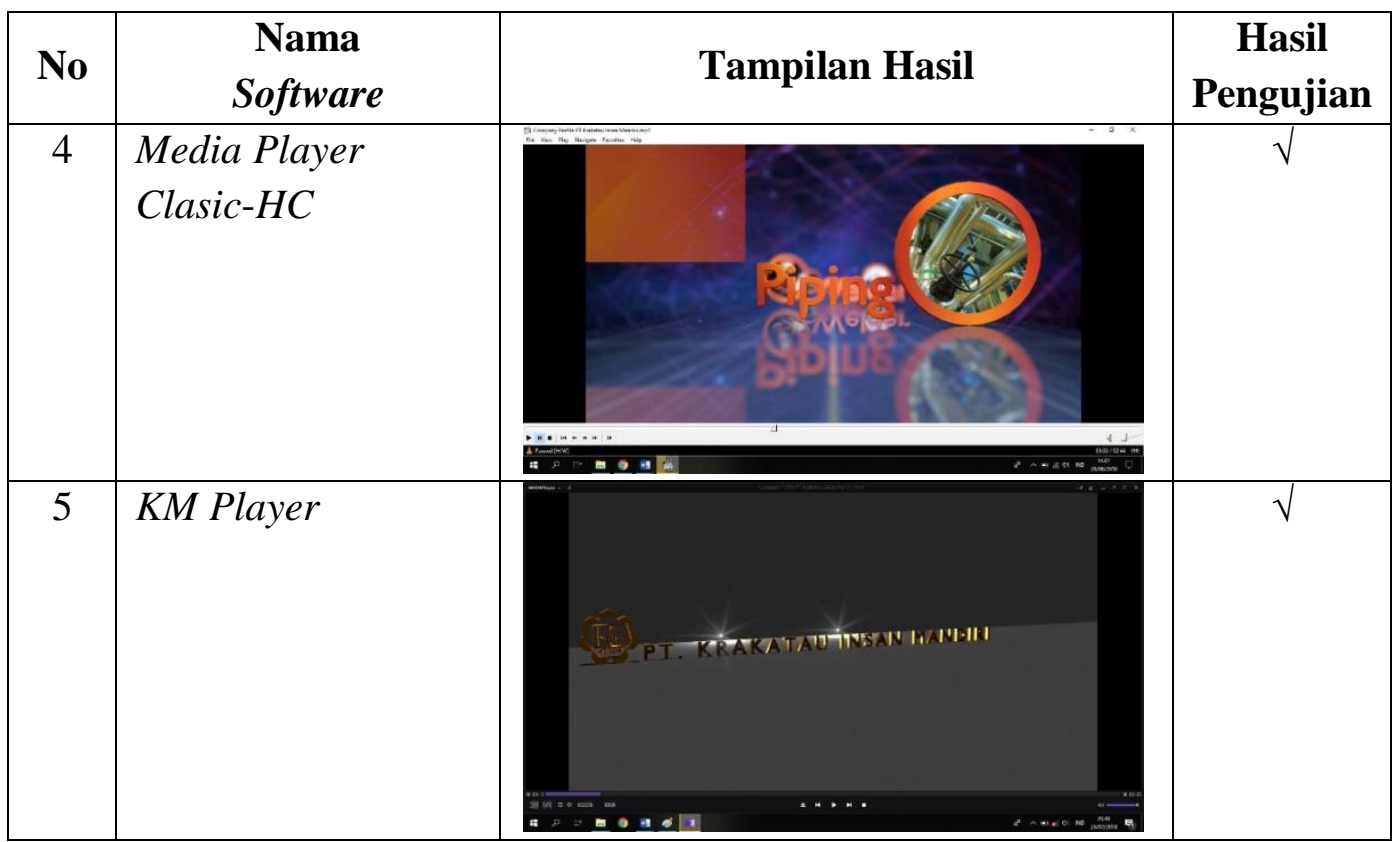

\section{Distribusi (Distribution)}

Pada tahap ini video animasi Profil Perusahaan PT. Krakatau Insan Mandiri di upload ke youtube agar dapat diterima oleh masyarakat luas terutama perusahaan-perusahaan dan juga di simpan dalam media penyimpanan berupa DVD (Digital Versatile Disc), kemudian dikemas ke dalam DVD case yang telah diberi cover untuk dokumen perusahaan itu sendiri.

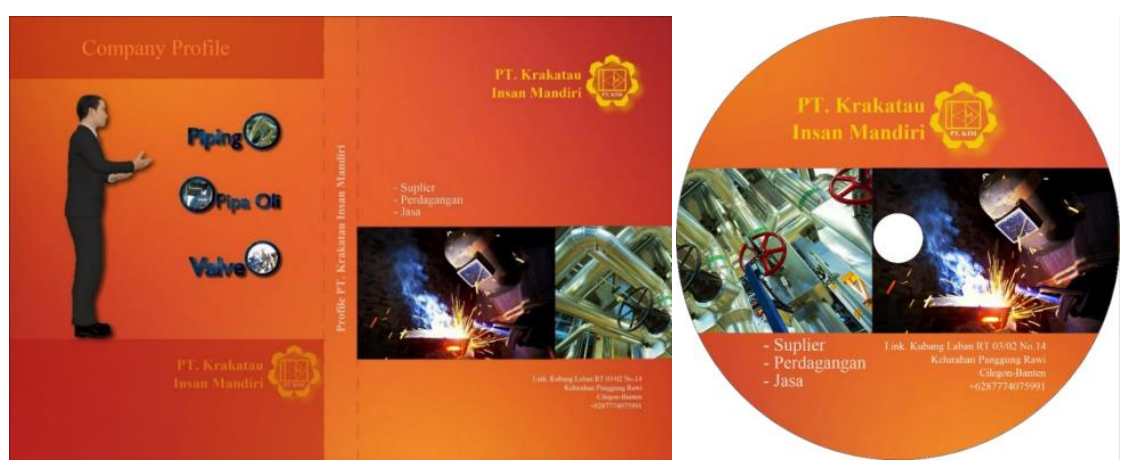

Gambar 11. Proses Distribution 


\section{KESIMPULAN}

1) Membuat video sederhana yang dapat memudahkan para konsumen untuk mengetahui perusahaan baik dari segi data perusahaan, visi dan misi yang dapat dibuat dengan metode perancangan perangkat lunak versi Luther Sutopo menggunakan lima aplikasi bantuan sekaligus yaitu Corel Draw, MakeHuman, Blender 3D, Adobe Premiere Pro, Audacity dan di upload ke youtube.

2) Media informasi berupa profil perusahaan berbasis animasi $3 \mathrm{D}$ yang di implementasikan melalui proses pengujian alfa dan beta, dimana hasil dari pengujian tersebut sudah cukup berhasil berdasarkan hasil dari pengujian beta dan profil perusahaan berbasis animasi 3D ini di simpan dalam media penyimpanan berupa DVD dengan format mp4. Selain itu profil perusahaan tersebut akan di sebar luaskan melalu media youtube untuk memperkenalkan PT. Krakatau Insan Mandiri.

\section{DAFTAR PUSTAKA}

Ahmad Mujibi. (2014). Judul Skripsi "Rancang Bangun Video Company ProfilePada Lembaga Pendidikan Islam Pondok Pesantren Daarul Ahsan Jayanti - Tangerang Berbasis Multimedia". Nim : 11210191. Program Studi Teknik Informatika, Fakultas Teknologi Informasi, Universitas Serang Raya.

Binus. (2016). "Alpha dan Beta Testing". Tersedia :https://sis.binus.ac.id/2016/12/16/ [13 Januari 2018].

Budiman, Muhammad Adri, Dedy Irfan. (2016). "Perancangan Media Presentasi Company Profile Universitas Negeri Padang Berbasis Multimedia Interaktif'. [Online] Jurnal Vokasional Teknik Elektronika dan Informatika. Tersedia :

http://ejournal.unp.ac.id/index.php/voteknika/article/viewFile/6421/4972[19 Oktober 2017] .

Eggi Agitsni. (2017). Judul Skripsi "Perancangan Metode Storrytelling dalam Pelajaran Muthola'ah Kelas 1 MA di Pondok Pesantren Modern Berbasis Animasi 3D”. Nim : 11213112. No. Skripsi : 081/SKRIPSI/TIUNSERA/S1/X/2017. Program Studi Teknik Informatika, Fakultas Teknologi Informasi, Universitas Serang Raya.

Hog Pictures. (2017). "Pengertian dan Sejarah Adobe Premiere Pro". Tersedia :http://www.hog-pictures.com/2015/11/pengertian-adobe-premiere-prohistory.html [19 Oktober 2017]. 
Komputer Lamongan. (2016). "Pengertian dan keunggulan Serta Kegunaan Corel Draw". Tersedia : http://komputerlamongan.com/pengertian-dankeunggulan-serta-kegunaan-corel-draw/ [16 Mei 2018].

Lawyerment. (2018). "Make Human Review". Tersedia : https://www.lawyerment.com/downloads/Graphics_and_Drawing/CAD_3 D_Design_and_Modeling/Review_19712_index.htm [16 Mei 2018].

Moh. Alif Cindi Momintan, Rizky Sukma. (2013). "Perancangan Company Profile The Geek Apple Authorished Reseller Yogyakarta Berbasis MultimediaFlash Sebagai Sarana Promosi dan Informasi”. [Online] Jurnal Ilmiah DASI. Tersedia : https://media.neliti.com/media/publications/89726ID-none.pdf [19 Oktober 2017] .

Mohammad Irfan. (2013). "Pembuatan Video Company Profile Pada Belukar Merch Di Kelurahan Jayengan Kecamatan Serengan Kota Surakarta" [Online] Seminar Riset Unggulan Nasional Informatika dan Komputer. Tersedia : http://ijns.org/journal/index.php/seruni/article/view/666 [13 Januari 2018].

Munir. (2015). Judul Buku "Multimedia Konsep \& Aplikasi Dalam Pendidikan". Penerbit Alfabeta, Bandung. Cetakan Ketiga : Desember 2015. ISBN : 978602-7825-04-8.

Sri Jarwati, Gesang Kristianto Nugroho. (2014). "Pembuatan Video Profil Akademi Kebidanan Mitra Husada Karanganyar Berbasis Multimedia". [Online] Open Journal Systems. Tersedia : http://ijns.org/journal/index.php/speed/article/view/1062 [13 Januari 2018].

Tri Haryanto, Sarwo Nugroho. (2015). "Perancangan Video Company Profile Sebagai Media Promosi Perusahaan Pada PT. Propan Raya ICC Semarang”. [Online] Vol. 8 No.1 $\quad$ - $\quad$ PIXEL. Tersedia : https://drive.google.com/file/d/0B0EdWn-d3T9xcjJybkpJWU1ISnM/view [19 Oktober 2017]. 